\title{
Pengaruh Mendengarkan Dan Membaca Sholawat Terhadap Tingkat Kecemasan Pasien Post OP ORIF DI RSUD Ngudi Waluyo Wlingi
}

\author{
Niafatun Nofiah ',2, Fitri Arofiati ', Yanuar Primanda ' \\ 1Magister Keperawatan Universitas Muhammadiah Yogyakarta Jl. Brawijaya, Kasihan, \\ Geblagan, Tamantirto, Kasihan, Bantul, Daerah Istimewa Yogyakarta 55183, \\ 2Universitas Wahidiyah Kediri \\ Korespondensi Email : niafatun@gmail.com
}

DOI: $10.33859 / \mathrm{dksm} . v 10 \mathrm{il} .415$

Abstrak
Latar Belakang: Open reduction internal fixationORIF merupakan salah satu penatalaksanaan pada
kasus fraktur yang menggunakan tehnik pembedahan, dan pembedahan tersebut dapat mengakibatkan
ketidaknyamanan dan kecemasan pada pasien. Untuk mengatasi kecemasan dapat menggunakan
terapi non farmakologi dengan tehnik distraksi, salah satu nya mendengarkan dan membaca
Sholawat.
Tujuan: Untuk mengetahui pengaruh pemberian intervensi mendengarkan dan membaca Sholawat
terhadap tingkat Kecemasan pasien Post Op ORIF di RSUD Ngudi Waluyo Wlingi.
Metode: Penelitian ini merupakan penelitian kuantitatif dengan jenis pre eksperiment dengan one
group pretest-posttest, tehnik sampling yang digunakan yaitu Accidental sampling, sampel pada
penelitian ini yaitu pasien dengan Post Op ORIF dan di dapatkan 32 responden. Instrument yang di
gunakan yaitu MP3 dan headset yang berisi rekaman Sholawat, serta kuasioner HARS untuk menilai
tingkat kecemasan pasien.
Hasil: Hasil dalam penelitian di dapatkan adanya penurunan tingkat kecemasan setelah diberikan
intervensi secara signifikan, dan analisis di gunakan yaitu Uji Wilcoxon dan mendapatkan
hasil p value 0.000 (p<0.05),
Kesimpulan: Terdapat pengaruh yang signifikan pada pemberian intervensi mendengarkan dan
membaca Sholawat terhadap tingkat kecemasan pasien Post Op ORIF di RSUD Ngudi Waluyo
Wlingi.
Kata kunci: Sholawat, tingkat kecemasan, ORIF




\title{
Effect of Listening and Reading Sholawat To Anxiety Level of Post OP ORIF Patients In Ngudi Waluyo Wlingi Hospital
}

\begin{abstract}
Background: open reduction internal fixtation (ORIF) is one of fracture management that reguires surgical prosedur which coused unfortable an anxiety. Listeing and reading Sholawat is one of distraction methods to reduce anxiety.

Objective: The object of this study was to examine the effect of listening and reading Sholawat on anxiety level among patients with ORIF in RSUD Ngudi Waluyo Wlingi.

Method: This was Pre-experimental study with one-group pre-post test. 32 respondents were selected through accidental sampling. The Sholawat recording was tested for validity and given to the respondent by using Mp3 and headset. The HARS questionnaire was used to test anxiety level.

Results: The result of this study showed that listening and reading Sholawat signyficanthy decreased anxiety level among patients with ORIF $p$ value 0,000

Conclusion: There was an effect of listening and reading Sholawat on patient's anxiety level.

Keywords: Prayer, level of anxiety, ORIF
\end{abstract}

\section{PENDAHULUAN}

ORIF merupakan salah satu penatalaksanaan pada kasus fraktur dengan cara prosedur bedah medis yang tindakanya secara operasi terbuka untuk mengatur struktur tulang, seperti pada kasus patah tulang, fiksasi internal ini mengacu pada fiksasi sekrup dan piring untuk proses penyembuhan (Potter \& Perry, 2009). Adanya pembedahan mengakibatkan munculnya masalah keperawatan berupa kecemasan.

Kecemasan merupakan suatu perasaan subjektif mengenai ketegangan mental yang menggelisahkan sebagai reaksi umum dari ketidakmampuan mengatasi suatu masalah atau tidak adanya rasa aman (Rochman, 2010). Penatalaksanaan untuk masalah kecemasan perawat menggunakan pendekatan non farmakologi dengan cara distraksi, seperti beberapa penelitian yang menggunkan tehnik distraksi berupa mendengarkan music.

Seperti pada penelitian Alerd et al (2010), mencatat bahwa penggunaan terapi musik dapat menurunkan rasa sakit, namun penurunan hanya sedikit dan signifikasi klinisnya tidak pasti. Penelitian terdahulu 
Dinamika Kesehatan Jurnal Kebidanan dan Keperawatan Vol 10 No. 1 Juli 2019 (ISSN: 2086-3454 EISSN: 2549-4058) url: http://ojs.dinamikakesehatan.unism.ac.id DOI : https://doi.org/10.33859/dksm.v10i1

Pengaruh Mendengarkan Dan Membaca Sholawat Terhadap Tingkat Kecemasan Pasien Post OP ORIF DI RSUD Ngudi Waluyo Wlingi

menyarankan agar tidak hanya memeriksa nyeri tetapi juga mencakup kecemasan. Untuk pasien yang alami nyeri akut, pengobatan untuk kecemasan sangat dibutuhkan, karena kecemasan sering meningkatkan persepsi rasa sakit, namun rasa sakit juga bisa menimbulkan rasa cemas.

Tehnik distraksi dengan cara mendengarkan dapat juga dengan mendengarkan murottal al-quran, seperti pada penelitian Faradisi (2010) mengenai perbandingan terapi music klasik dengan terapi murotal terhadap kecemasan pra operasi pada pasien dewasa di Indonesia, menunjukkan bahwa terapi murottal secara statistik memperoleh $\mathrm{p}<0,05$ dalam mengurangi kecemasan. Hal ini dikarenakan masyarakat Indonesia tidak mengenal musik klasik. Sementara murottal adalah dimensi seni yang ada dalam Islam dan ini sangat dikenal masyarakat Islam khususnya dii Indonesia`.

Pada penelitian ini peneliti memberikan intervensi berupa mendengarkan Sholawat. Bersholawat kepada Nabi juga mempunyai manfaat yang baik sebagai salah satu cara berdo'a diberbagai keadaan yang dapat di gunakan untuk menyembuhkan rasa sakit dan apabila di baca berulang-ulang kali dapat menghilangkan rasa was-was dan kecemasan, dan sebagai tehnik untuk mengalihkan perhatian ke stimulus lain (Elfaruqi, 2016).

\section{Metode}

Penelitian ini menggunakan desain pre eksperimen dengan one-group pre test-post test dengan intervensi mendengarkan dan membaca Sholawat. Tehnik pengambilan sampel menggunkan Accidental Sampling dan di dapatkan 32 responden yang sesuai dengan kriteria inklusi berupa Post Op ORIF hari 0, usia 18-65 tahun, beraagama islam, nilai HARS 14-56 dan tidak mengalami gangguan pendengaran dan ktiteria esklusi berupa responden tidak mengikuti proses penelitian sampai selesei dan responden yang mengundurkan diri.

Sampel pada penelitian ini ialah pasien Post Op ORIF di ruang Bougenvile RSUD Ngudi Waluyo Wlingi. Variabel pada 
penelitian ini yaitu mendengarkan dan membaca Sholawat dan Tingkat Kecemasan. Pengambilan data pada penelitian ini di laksanakan pada bulan Agustus-September 2018 di Ruang Bougenvile RSUD Ngudi Waluyo Wlingi.

Pemberian intervensi mendengarkan dan membaca Sholawat dengan cara mendengarkan melalui Mp3 dan headset yang berisi rekaman Sholawat Tibb'il Qulub dan Sholawat Nariyah yang di lantunkan oleh Muhammad Yusuf yang sudah di uji dan di analisa dengan Softwere Steinberg Neundo dengan hasil tempo sholawat Nariyah 68,7-77 BPM dan sholawat Tib'il Qulub dengan tempo 60-80 BPM, dan menyimak teks Sholawat sekitar 20-30 menit 2 kali dalam sehari selama 3 hari. Dengan posisi senyaman mungkin menurut pasien.

Penilaian pada tingkat kecemasan menggunakan kuasioner HARS yang mempunyai 14 bagian dengan nilai validitas $r=$ 0,91 dan reliabilitas $\mathrm{r}=0,975$. Uji parametrik Wilcoxon di gunakan untuk mengetahui nilai tingkat kecemasan sebelum dan sesudah diberikan intervensi. Penelitian ini telah di lakukan uji etik di Fakultas Kedokteran Universitas Muhammadiyah Yogyakarta dengan nomor surat 315/EP/-FKIKUMY/VI/2018.

\section{Hasil}

1. Gambaran karakteristik responden Tabel 1 Distribusi Frekuensi Karakteristik Responden Berdasarkan Data Demografi Responden Post Op ORIF Di RSUD Ngudi Waluyo Wlingi ( $\mathrm{N}=32$ )

\begin{tabular}{|c|c|c|}
\hline Karakteristik & $d f$ & $\%$ \\
\hline \multicolumn{3}{|l|}{ Jenis kelamin } \\
\hline Perempuan & 17 & 53.1 \\
\hline Laki-laki & 15 & 46.9 \\
\hline Karakteristik & $d f$ & $\%$ \\
\hline \multicolumn{3}{|l|}{ Pendidikan } \\
\hline $\mathrm{SD}$ & 11 & 34.4 \\
\hline SMP & 8 & 25.0 \\
\hline SMA & 9 & 28.1 \\
\hline S1 & 4 & 12.5 \\
\hline \multicolumn{3}{|l|}{ Lokasi operasi ORIF } \\
\hline Cruris & 8 & 25.0 \\
\hline Radius & 4 & 12.5 \\
\hline Tibia & 8 & 25.0 \\
\hline Humerus & 4 & 12.5 \\
\hline Femur & 7 & 21.9 \\
\hline Meta parsal & 1 & 3.1 \\
\hline \multicolumn{3}{|l|}{ Obat yang dikonsumsi } \\
\hline Cefotaxin, Ketorolac, & 4 & 12.5 \\
\hline Ranitidin & 28 & 87.5 \\
\hline \multicolumn{3}{|l|}{ Riwayat Operasi } \\
\hline Pernah & 7 & 21.9 \\
\hline Belum pernah & 25 & 78.1 \\
\hline \multicolumn{3}{|l|}{ Menjalankan sholat wajib } \\
\hline $\begin{array}{l}5 \text { waktu } \\
\text { Ya }\end{array}$ & 32 & 100.0 \\
\hline \multicolumn{3}{|l|}{$\begin{array}{l}\text { Sholawat yang pernah di } \\
\text { dengarkan dan di baca }\end{array}$} \\
\hline Nariyah & 4 & 12.5 \\
\hline Nariyah, Tibi’il Qulub & 27 & 84.4 \\
\hline $\begin{array}{l}\text { Nariyah, Tibi'il qulub, } \\
\text { Badar, Munjiyat }\end{array}$ & 1 & 3.1 \\
\hline \multicolumn{3}{|l|}{$\begin{array}{l}\text { Kepercayaan } \\
\text { mendengarkan dan } \\
\text { membaca sholawat dapat } \\
\text { menurunkan nyeri dan } \\
\text { kecemasan }\end{array}$} \\
\hline $\mathrm{Ya}$ & 26 & 81.2 \\
\hline Ragu-ragu & 6 & 18.8 \\
\hline $\begin{array}{l}\text { Keyakinan } \\
\text { mendengarkan dan } \\
\text { membaca sholawat dapat } \\
\text { menurunkan nyeri dan }\end{array}$ & & \\
\hline kecemasan & 6 & 18.8 \\
\hline Sangat yakin & 20 & 62.5 \\
\hline Yakin & 6 & 18.8 \\
\hline Cukup yakin & & \\
\hline
\end{tabular}


Sumber: Data primer 2018

Berdasarkan data di atas menjelaskan bahwa responden pada jenis kelamin di dapatkan data sebagian besar adalah responden perempuan sejumlah 17 responden $(53.1 \%)$. Pendidikan responden mayoritas adalah SD sejumlah 11 responden $(34.4 \%)$.

Berdasarkan lokasi operasi ORIF di dapatkan data terbanyak lokasi operasi pada bagian Cruris $25.0 \%$ dan bagian Tibia $25.0 \%$. Obat yang di konsumsi oleh rsponden, seluruhnya mendapat analgesik ketorolac, dan sebagian responden mendapat tambahan obat berupa cefotaxin dan ranitidine sejumlah sejumlah 28 responden $(87.5 \%)$.

Berdasarkan riwayat operasi, sebagian besar responden belum pernah menjalani operasi, dan data yang didapatkan sejumlah 25 responden $(78.1 \%)$. Semua responden tetap melakukan sholat dalam kondisi sehat maupun dalam kondisi sakit. Sholawat yang pernah di dengar dan dibaca oleh responden sebagian besar adalah sholawat Nariyah dan Tibi'il Qulub dengan sebanyak 27 responden (84.4
$\%$ ) yang mendengarkan dan membaca

Sholawat.

Mayoritas responden percaya terhadap mendengarkan dan membaca sholawat dapat menurunkan nyeri dan kecemasan, dengan jumlah 26 responden $(81,2 \%)$. Sebagian besar responden juga yakin bahwa mendengarkan dan membaca sholawat dapat menurunkan nyeri dan kecemasan di dapatkan dengan jumlah sebanyak 20 responden $(62.5 \%)$.

Tabel 2.Distribusi frekuensi berdasarkan usia responden Post Op ORIF di RSUD Ngudi Waluyo Wlingi $(\mathrm{n}=32)$

\begin{tabular}{ccc}
\hline & Mean $\pm \boldsymbol{S D}$ & Min-max \\
\hline Usia & $43.44 \pm 12.705$ & $18-63$ \\
\hline & Menunjukan data bahwa rata-rata usia
\end{tabular}

responden 43.44 tahun dengan standart deviasi

12.705. usia termuda 18 tahun dan usia tertua 63 tahun.

Tabel 3 Distribusi Tingkat Kecemasan responden Post Op ORIF

\begin{tabular}{|c|c|c|}
\hline & Mean $\pm S D$ & $\begin{array}{l}\text { Min- } \\
\max \end{array}$ \\
\hline Pre intervensi & $31.91 \pm 7.977$ & $14-48$ \\
\hline Post intervensi & $15.16 \pm 4.893$ & $6-31$ \\
\hline
\end{tabular}

kecemasan pada pre intervensi di dapatkan 31.91 dengan standar devisiasi 7.977, dengan nilai nyeri minimal 14 dan nilai maksimal 48. Nilai rata-rata tingkat kecemasan pada post intervensi di dapatkan 15.16 dengan standar devisiasi 4.893, nilai kecemasan minimal 6 dan nilai maksimal 31. 
2. Pengaruh mendengarkan dan membaca sholawat terhadap tingkat kecemasan pasien Post Op ORIF di RSUD Ngudi Waluyo Wlingi.

Tabel 4 Hasil Uji Wilcoxon analisis nilai tingkat kecemasan pada intervensi mendengarkan dan membaca sholawat terhadap pasien Post Op ORIF di RSUD Ngudi Waluyo Wlingi.

\begin{tabular}{lcc}
\hline & $\begin{array}{c}\text { Median } \\
(\text { min-max })\end{array}$ & Nilai $p$ \\
\hline $\begin{array}{l}\text { Pre } \\
\text { intervensi }\end{array}$ & $32(14-48)$ & 0.000 \\
$\begin{array}{l}\text { Post } \\
\text { intervensi }\end{array}$ & $14(6-31)$ & \\
\hline
\end{tabular}

Sumber: Data primer 2018

Nilai median tingkat kecemasan responden sebelum di berikan intervensi 32 dengan nilai minimum 14 dan nilai maximum 48. Nilai median setelah diberikan intervensi 14 dengan nilai minimum 6 dan nilai maximum 31. Hal ini menunjukan adanya penurunan tingkat kecemasan setelah diberikan intervensi mendengarkan dan membaca sholawat. Hasil uji Wilcoxon diperoleh $p$ value $0.000<0.05$ yang berarti Ho ditolak, sehingga ada pengaruh pemberian intervensi mendengarkan dan membaca sholawat terhadap tingkat kecemasan pasien

\section{Post Op ORIF di RSUD Ngudi Waluyo}

Wlingi.

\section{PEMBAHASAN}

Hasil penelitian ini menunjukan terdapat penurunan tingkat kecemasan secara signifikan sebelum dan sesudah diberikan intervensi. Penelitian ini memberikan intervensi berupa mendengarkan dan membaca Sholawat.

Kecemasan merupakan sinyal yang memeperingatkan adanya ancaman bahaya pada seseorang dan memungkinkan seseorag untuk mengambil tindakan untuk mengatasi ancaman tersebut. Dari teori psiko-fisilogis kecemasan akan mempengaruhi denyut jantung,t dan pernafasan (Kaplan et.,all, 2010 dalam Faradisi, 2018).

Kecemasan yang terjadi pada pasien post Operasi ORIF akan berdampak terhadap proses penyembuhan. Ketika pasien mengalami kecemasan pada masa post operasi, maka akan berpengaruh pada lamanya proses penyembuhan. Pada penelitian Roh, et. all (2014) di temukan pada pasien fraktur yang mengalami operasi, terdapat hubungan antara 
tingkat kecemasan dan pasien yang sedang dalam proses penyembuhan setlah tindakan operasi. Kecemasan yang tidak di atasi dengan baik akan mempengaruhi pada proses recovery menjadi lebih lama.

Menurut Starr (2011) dalam penelitianya menjelaskan, pada pasien dengan trauma orthopedik, faktor psikologis merupakan faktor yag penting untuk menentukan hasil fungsional dari pasien. Keadaan psikologis pasien akan terganggu dalam hal penyembuhan setelah cedera tidak akan sepenuhnya baik, dan berdampak pada stress fisik atau emosional di masa yang akan datang.

Stress fisik atau emosional mengaktivasi amygdala yang merupakan bagian dari system limbic berhubungan dengan komponen emosional otak. Respon emosional yang timbul ditahan oleh input dari pusat yang lebih tinggi di ferobrain. Respon neurologis dari amygdale ditrasmisikan dan menstimulasi hormone CRF (corticropinreleasing factor) yang menstimulasi hipofisis untuk melepaskan hormone lain yaitu ACTH (andrenocorticotropic hormone) ke dalam darah. ACTH sebagai ganti untuk menstimulasi kelenjar adrenal menghasilkan kortisol, suatu kelenjar kecil yang berada di atas ginjal. Semakin berat stress maka kelenjar adrenal akan menghasilkan kortisol lebih banyak dan menekan system imun (Guyton, 2009).

Seseorang yang mengalami ketegangan dan kecemasan yang bekerja adalah sistem syaraf simpatis dan pada waktu rilesk yang bekerja adalah sistem syaraf simpatis. Keadaan yang rileks akan menurunkan aktivitas amygdala, mengendurkan otot, dan melatih individu untuk mengaktifkan sistem syaraf parasimpatis sebagai counter aktivitas saraf simpatis (Maimunah, 2011).

Hipotalamus bekerja secara langsung pada sistem otonom untuk merangsang respon terhadap stress. System otonom sendiri diperlukan dalam menjaga keseimbangan tubuh. System otonom terbagi menjadi dua bagian yaitu system simpatis dan parasimpatis. Sistem simpatis bertanggung jawab terhadap 
adanya stimulasi atau stress. Reaksi yang timbul berupa peningkatan denyut jantung, nafas cepat dan penurunan aktivitas gastrointestinal. Sistem parasispatis membuat tubuh kembali kekeadaan istirahat melalui penurunan denyut jantung, perlambatan pernafasan, meningkatkan aktivitas gastrointestinal. Stimulasi yang berkelanjutan terhadap system saraf sispatis menimbulkan respon stress yang berulang-ulang dan menempatkan system saraf otonom pada keseimbangan system yang penting bagi kesehatan tubuh.

Tubuh dipersiapkan untuk melawan atau reaksi menghindari melalui satu mekanisme rangkap, satu respon saraf jangka pendek dan satu respon hormonal yang bersifat lebih lama (Guyton, 2009).

Ansietas menyebabkan respon kognitif, psikomotor, dan fisiologis yang tidak nyaman, misalnya peningkatan aktivitas motorik, agitasi, kesulitan berfikir secara logis dan peningkatan tanda-tanda vital. Seseorang mencoba untuk mengurangi tingkat ketidaknyaman dengan mekanisme pertahanan. Perilaku yang adaptif akan mejadi hal yang positif dan membantu individu adaptasi dan belajar, seperti cara mengggunakan tehnik imajinasi untuk memfokuskan perhatian pada pemandangan yang indah, relaksasi tubuh dan pernafasan yang teratur untuk mengurangi ketegangan otot dan tanda-tanda vital. Respon negative terhadap ansietas dapat menimbulkan perilaku mal adaptif seperti terjadi sindroma nyeri, sakit kepala dan respon yang menimbulkan efisien imun (Wirnata, 2012).

Hal ini sesuai dengan penelitian yang di lakukan oleh Atik (2010) yang melihat pengaruh sholawat terhadap tingkat kecemasan pada pengguna narkobaa yang mendapatkan hasil signifikan, penelitian tersebut di lakukan dengan cara membrikan intervensi membaca sholawat dengan metode meditasi untuk melatih meningkatkan perhatian dan taraf kesadaran yang dapat membawa proses-proses mental dapat terkonntrol secara sadar. Penelitian tersebut juga menunjukan hasil dari wawancara pada sebagian responden yang mengikuti terapi 
membaca sholawat menyatakan bahwa ada perubahan perasaan menjadi tenang.

Sholawat ialah suatu kajian yang esensial dan bermanfaat untuk dikaji, Sholawat memilik makna yaitu penghormatan dan pengagungan terhadap Nabi Muhammad SAW dan sebagai suatu amalan ibadah (Azhar, 2017). Hal ini selaras dengan firman Alloh SWT "sesungguhnya Alloh dan malaikatmalaikatNya, bershalawat atas Nabi, wahai orang-orang yang beriman, bershalawatlah untuk Nabi dan ucapkan salam penghormatan kepadanya”.(Qs. Al-Ahzab 56).

Sholawat mempunyai manfaat untuk menghilangkan kesulitan dan rasa kecemasan yang di derita seseorang. Di kalangan umat islam, keyakinan kepada Alloh SWT dapat membantu apabila seseorang mengalami masalah atau sakit, mereka percaya bahwa permohonan mereka akan di terima sehingga dapat membantu mereka untuk memperkuat jiwa, tubuh dan fikiran, sehingga sistem saraf otonom berkurang dan menurunka respon fisiologis (Soliman \& Mohammed, 2013).

\section{Kesimpulan}

Kesimpulan dari hasil penelitian ini adalah terdapat pengaruh mendengarkan dan membaca Sholawat terhadap tingkat kecemasan pada pasien Post Op ORIF di RSUD Ngudi Waluyo Wlingi.

\section{TERIMA KASIH}

dr. Endah Woro Utami, MMRS selaku direktur RSUD Ngudi Waluyo Wlingi yang telah memberikan ijin penelitian di RSUD Ngudi WaluyoWlingi.

\section{DAFTAR PUSTAKA}

Allred et al., (2010) The effect of music on postoperative pain \& anxiety. Pain managemen nursing, 11, 15-25.

Azhar, Y C. (2017). "perspektif shalawat di dalam al-qur'an dan al-hadits serta implikasinya di dalam penafsiran dan penetapan hukum.” Basis 1, no. 1

Dawana, S. (2010). Sex Differences in Pain and Pain-Related Disability among Primary Care Patients with Chronic Musculoskeletal Pain. American Academy of Pain Medicine Pain, 11, 232-239

Eko, S. (2015). "Nilai-Nilai Religius Dalam Syair Shalawat Burdah." Lingua: Jurnal Ilmu Bahasa Dan Sastra 10, no. 1: 1-8

El-faruqi, A.A. (2016). Kitab Lengkap Shalat, Dzikir, Doa, Shalawat, Asmaul Husna cet. 1- Yogyakarta: Sabil.

Faradisi, F. (2010). Differences Effectivenes Between Murotal Therapy With Music 
Clasik Therapy To Decline In The Level Of Anxious On Patients Pre Operation Fraktur Extremity [Bachelor Thesis in Adult Nursing]. Surakarta: Muhammadiyah University of Surakarta.

Faradisi, Firman, and Nurul Aktifah. "Pengaruh Pemberian Terapi Murottal Terhadap Penurunan Kecemasan Post Operasi." Profesi (Profesional Islam): Media Publikasi Penelitian 15, no. 2 (2018): 6.

Maimunah, A. (2011). Pengaruh pelatihan relaksasi dengan dzikir untuk mengatasi kecemasan ibu hamil pertama. Psikologi Islam, 8(1), 1-22

Mardiani, Atik (2017). "Pengaruh membaca Sholawat Wahidiyah terhadap tingkat kecemasan pengguna narkoba" di akses tanggal 20 Oktober 2018

Guyton \& Hall. (2009). Buku ajar fisiologis kedokteran. EGC.Jakarta.

Potter. P. A \& Perry, A.G. (2009). Fundamental Keperawatan Edisi 7 Buku 1 dan 2. Jakarta. Salemba Medika.

Potter \& Perry. (2011). Basic Nursing. Canada: Mosby Elsevier.

Roh, Y. H., dkk. (2014). Effect of Anxietyand Catastrophic Pain Ideation on Early Recovery After Surgery for Distal Radius Fractures. The Journal of Hand Surgery.

Romani, N.K., Hendarsih, S., \& Asmarani, F.L. (2013). Hubungan Mekanisme Koping dengan Tingkat Kecemasan pada Pasien Gagal Ginjal Kronis di Unit Hemodialisa RSUP Dr. Soeradji Tirtonegoro Klaten. Universitas Respati Yogyakarta.

Soliman, H, \& Mohamed, S. "Effects of Zikr Meditation and Jaw Relaxation on Postoperative Pain, Anxiety and
Physiologic Response of Patients Undergoing Abdominal Surgery." Journal of Biology, Agriculture and Healthcare 3, no. 2 (2013): 23-38.

Tamama, R (2016). "Religious Counseling: Overcoming Anxiety with the Adoption of Religiopsikoneuroimunologi Based Remembrance Therapy". Jurnal KOPASTA, 3(2), 2016 Available online at www.journal.unrika.ac.id 